\title{
Fournier's gangrene in a pediatric patient after prolonged neglected diarrhea: A case report
}

\author{
Sujoy Neogi, Piare Lal Kariholu, Deepak Chatterjee, \\ Brajesh Kumar Singh, Rajnish Kumar
}

\begin{abstract}
Introduction: Fournier's gangrene in pediatric population is rare and because of low incidence the etiopathogenesis in children is not well known. Case Report: We report a rare case of a 10-month-old male infant with severe Fournier's gangrene occurring after an episode of prolonged diarrhea. The progression of the disease was very fast and in spite of undergoing a diversion transverse colostomy, the child could not survive. Conclusion: Fournier's gangrene in children is rare and the course of the illness in our case was very rapid. The relation of this severe form of fasciitis with a common condition like diarrhea is rare and must be known to the treating clinicians.
\end{abstract}

Keywords: Fournier's gangrene, Perineal ulcer, Pediatric, Diarrhea complication, Necrotizing fasciitis

Sujoy Neogi ${ }^{1}$, Piare Lal Kariholu², Deepak Chatterjee ${ }^{3}$, Brajesh Kumar Singh ${ }^{4}$, Rajnish Kumar ${ }^{4}$

Affiliations: ${ }^{1}$ (DNB Pediatric Surgery), Assistant Professor, Department of Surgery, School of Medical Science and Research \& Sharda Hospital Sharda University, Greater Noida, UP, India; ${ }^{2}$ (MS), Professor, Department of Surgery, School of Medical Science and Research \& Sharda Hospital Sharda University, Greater Noida, UP, India; ${ }^{3}(\mathrm{MS})$, Assistant Professor, Department of Surgery, School of Medical Science and Research \& Sharda Hospital Sharda University, Greater Noida, UP, India; ${ }^{4}(\mathrm{MS})$, Senior Resident, Department of Surgery, School of Medical Science and Research \& Sharda Hospital Sharda University, Greater Noida, UP, India.

Corresponding Author: Dr. Sujoy Neogi, Flat 405, Dakshinayan Apartment, Sector 4, Plot 19, Dwarka, Delhi, India 110075; Mob: +91 9711196682; Email: drsujoyneogi@yahoo.com

Received: 14 September 2012

Accepted: 17 October 2012

Published: 01 February 2013
Neogi S, Kariholu PL, Chatterjee D, Singh BK, Kumar R. Fournier's gangrene in a pediatric patient after prolonged neglected diarrhea: A case report. International Journal of Case Reports and Images 2013;4(2):135-137.

$$
* * * * * * * * *
$$

doi:10.5348/ijcri-2013-02-279-CR-13

\section{INTRODUCTION}

Fournier's gangrene is fascitis of the perineal region commonly seen in adult males with diabetes mellitus [1]. Pediatric involvement is rare. The use of nonsteroidal anti-inflamatory drugs (NSAID) have been found to be associated with Fournier's gangrene in children, besides other causes [1-6]. In the present case Fournier's gangrene was associated with neglected prolonged diarrhea, perianal excoriation resulting from diarrhea, and poor hygiene which has not been reported in literature so far. The use of NSAID may have also have contributed to the disease.

\section{CASE REPORT}

A 10-month-old male infant was brought by his mother to our emergency with a large ulcer in the perianal region for the last 10 days which was extending to the scrotum. The mother also complained that the child had decreased feed tolerance and decreased passage of stools. The child was ill for one month and his illness started with chest retractions, fever and diarrhea. He developed perianal excoriation following diarrhea, the intensity of which kept on increasing. The excoriation turned into a progressive ulcer including the perianal region and the scrotum. The progression of perianal disease was very fast and it reached the present 
form in only 10 days (Figure 1). The child kept passing stools which contaminated the wound further. The child had received treatment in the form of antibiotic (amoxycillin) and non-steroidal anti-Inflammatory drugs (NSAID) (Ibuprofen), which were given when the child developed excoriation. On examining the child, the pulse was $150 / \mathrm{min}$ (low volume), respiratory rate was 35/min. General physical examination revealed left complete cleft lip with complete cleft palate. The child also had bilateral rhonchi in the chest. Local examination of the perineum revealed a large ulcer measuring $7 \times 5 \mathrm{~cm}$ involving the anal canal and the perianal region. The anal canal was retracted up. There was another ulcer at the base of the scrotum measuring $3 \times 4 \mathrm{~cm}$ which was superficial extending up to the dartos muscle. The floor of both the ulcers was dirty with extensive sloughing. The hematological report was as

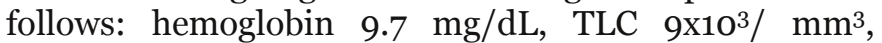
platelet count $0.44 \times 10^{6} / \mathrm{mm}^{3}$, blood urea $20 \mathrm{mg} / \mathrm{dL}$, serum creatinine $0.6 \mathrm{mg} / \mathrm{dL}$, sodium $144 \mathrm{mmol} / \mathrm{dL}$, potassium $2.9 \mathrm{mmol} / \mathrm{dL}$. The pus swab culture reported the growth of klebsiella species. The child was resuscitated adequately with fluids, antibiotics (ceftriaxone, metronidazole and amikacin), platelet transfusion and ionotropes for 24 hours and then posted for emergency transverse colostomy. A colostomy was performed, the ulcer was debrided and the child was catheterized. The child was kept in the intensive care unit on ventilator owing to the poor respiratory efforts in the post-operative period. The condition of the child kept deteriorating and he expired 18 hours after surgery due to multiorgan failure.

\section{DISCUSSION}

Fournier's gangrene is a necrotizing fasciitis of the perineal region. It is progressive and life threatening if not aggressively treated. It is seen more frequently in adults than children and is associated with

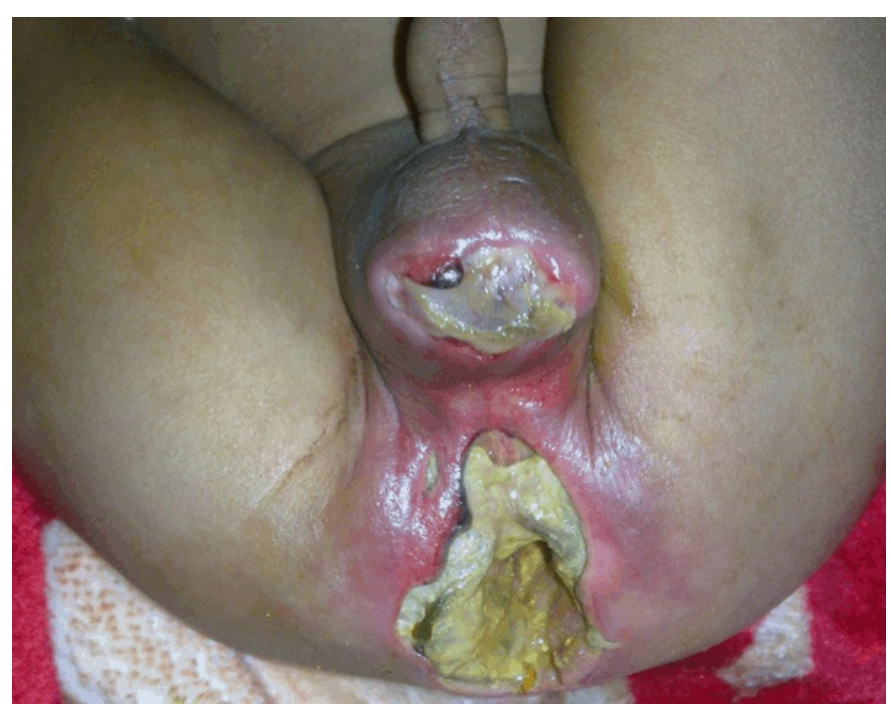

Figure 1: Clinical picture showing the perineal ulceration. immunosuppressant factors [1]. Very few cases of Fournier's gangrene have been reported in children [1]. The infection in Fournier's gangrene is polymicrobial and the bacteria act synergistically to produce enzymes such as collagenase and hyaluronidase that invade the fascial planes leading to vascular thrombosis with subsequent gangrene of the overlying skin [2]. The necrotizing fasciitis commonly originates from an infection of the anorectum, urogenital tract or the skin of the genitals [3]. The predisposing factors linked to Fournier's gangrene in children, which are mentioned in literature are NSAIDs use, post varicella infection, diaper rash, prematurity, circumcision, strangulated hernia, testicular torsion, trauma and insect bite [1, 4-6]. The treatment of Fournier's gangrene in children is equivocal. On one hand some studies favor medical management or conservative surgery in children [7-9], others advocate prompt and aggressive surgical debridement [4]. In our case, the child had diarrhea with perianal excoriation which progressed rapidly to a severe debilitating ulcer of the perineum. There was also a history of NSAIDs intake which has been described as a predisposing factor for Fournier's gangrene in children. We speculate in this case that it was the prolonged and neglected diarrhea along with the poor hygiene of the child which contributed to the rapidly developing fasciitis. This case was worth reporting because Fournier's gangrene is uncommon in the pediatric population. Also, the occurrence of this condition following diarrhea is a matter of concern as the incidence of diarrhea in developing countries is very high and therefore development of perianal excoriation should be prevented and promptly treated.

\section{CONCLUSION}

This is the first case report of severe, debilitating Founier's gangrene occurring in a child following prolonged diarrhea. Poor hygiene and improper treatment of the diarrhea have also contribute to the pathology. The role of NSAIDs cannot be confirmed, in causing this condition, although it has been given in our case for the treatment of perianal excoriation.

$$
* * * * * * * * *
$$

\section{Author Contributions}

Sujoy Neogi - Substantial contributions to conception and design, Acquisition of data, Drafting the article, revising it critically for important intellectual content, Final approval of the version to be published

Piare Lal Kariholu - Substantial contributions to conception and design, Acquisition of data, Drafting the article, revising it critically for important intellectual content, Final approval of the version to be published Deepak Chatterjee - Substantial contributions to conception and design, Acquisition of data, Drafting the article, revising it critically for important intellectual content, Final approval of the version to be published 
Brajesh Kumar Singh - Substantial contributions to conception and design, Acquisition of data, Drafting the article, revising it critically for important intellectual content, Final approval of the version to be published Rajnish Kumar - Substantial contributions to conception and design, Acquisition of data, Drafting the article, revising it critically for important intellectual content, Final approval of the version to be published

\section{Guarantor}

The corresponding author is the guarantor of submission.

\section{Conflict of Interest}

Authors declare no conflict of interest.

\section{Copyright}

(C) Sujoy Neogi et al. 2013; This article is distributed under the terms of Creative Commons Attribution 3.0 License which permits unrestricted use, distribution and reproduction in any means provided the original authors and original publisher are properly credited. (Please see www.ijcasereportsandimages.com/copyright-policy.php for more information.)

\section{REFERENCES}

1. Garcés C, Gómez C, Florez ID, Muñoz JD. [An unusual presentation of Fournier's gangrene. Is there a relationship with NSAID use? Pediatric case report]. Rev Chilena Infectol 2010;27(4):341-4.
2. Laucks SS 2nd. Fournier's gangrene. Surg Clin N Am 1994;74(6):1339-52.

3. Clayton MD, Fowler JE Jr, Sharifi R, Pearl RK. Causes, presentation and survival of fifty seven patients with necrotizing fasciitis of the male genitalia. Surg Gynecol Obstet 1990;170(1):49-55.

4. Dey S, Bhutia KL, Baruah AK, Kharga B, Mohanta PK, Singh VK. Neonatal Fournier's gangrene. Arch Iran med 2010;13(4):360-2.

5. Ameh EA, Dauda MM, Sabiu L, Mshelbwala PM, Mbibu HN, Nmadu PT. Fournier's gangrene in neonates and infants. Eur $J$ Pediatr Surg 2004;14(6):418-21.

6. Efem SE. The features and aetiology of Fournier's gangrene. Postgrad Med J 1994;70(826):568-71.

7. Ekingen $\mathrm{G}$, Isken $\mathrm{T}$, Agir $\mathrm{H}$, Oncel S, Günlemez A. Fournier's gangrene in childhood: a report of 3 infant patients. J Pediatr Surg 2008;43(12):e39-42.

8. Adams JR Jr, Mata JA, Venable DD, Culkin DJ, Bocchini JA Jr. Fournier's gangrene in children. Urology 1990;35(5):439-1.

9. Adeyokunnu AA. Fournier's syndrome in infants. A review of cases from Ibadan, Nigeria. Clin Pediatr 1983;22(2):101-3.
Access full text article on other devices

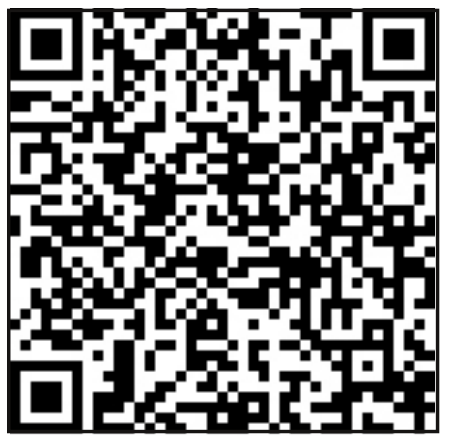

Access PDF of article on other devices

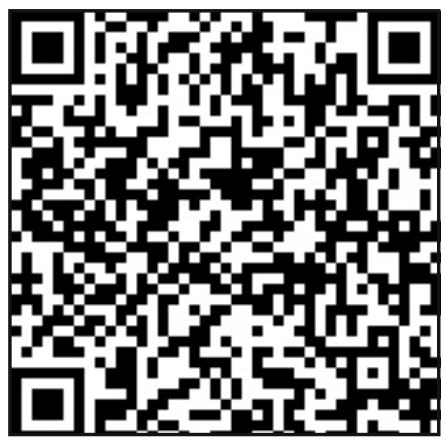

